\title{
Behavior of Biomphalaria glabrata Say, 1818 (Gastropoda: Planorbidae) - I. Morphophysiology of the Mantle Cavity
}

\author{
Pedro Jurberg $/ * /+$, Rodolfo A Cunha, Marcelo Luis Rodrigues
}

Laboratório de Comportamento, Departamento de Biologia, Instituto Oswaldo Cruz, Av. Brasil 4365, $21045-900$

Rio de Janeiro, RJ, Brasil *Instituto de Psicologia, Universidade do Estado do Rio de Janeiro,

Rio de Janeiro, Brasil

Using longitudinal and transverse anatomical sections, we observed that the three cristae of the mantle of Biomphalaria glabrata (renal, rectal and dorsolateral cristae) divide the mantle cavity into three chambers which we designated air or pulmonary chamber, water inflow chamber and water outflow chamber. Using videotape filming, we observed the inflow and outflow of air and water into and from the mantle cavity and we related their probable functions such as flotation, oxygen reservoir and transport, excreta circulation and elimination, water skeleton, and modification of specific weight. To determine whether the air bubble may function as a physical gill in this species we submitted three groups of snails to different systems in which water contained the same level of dissolved oxygen whereas the gas phases were atmospheric air, pure nitrogen or pure oxygen. We observed the following parameters: time of permanence on the surface, time of immersion, and frequency at which the snails reached the surface. These results did not demonstrate a physical gill function; morphological analysis of the mantle cavity indicates this possibility.

Key words: Biomphalaria glabrata - behavior - respiration - morphophysiology - mantle cavity

Biomphalaria glabrata lives in ditches, streams, water reservoirs, dams, wells, swamps and lagoons, and can even survive at sewage dumping sites, where it actually succeeds in proliferating abundantly (Freitas 1976). The snails are usually detected in surface waters near the margins (Andrade 1959, Paraense 1972, Appleton 1978) and can survive at a depth of $10 \mathrm{~m}$ when placed there (Deschiens \& Jadin 1954) or can even sink to this level spontaneously (Jurberg et al. 1987). In the laboratory, the snails withstand pressures corresponding to a depth of $50 \mathrm{~m}$ with no apparent damage (Jurberg et al. 1988, Jurberg 1992).

Furthermore, B. glabrata can also survive outside the water by aestivating (Olivier \& Barbosa 1956) or remain dormant for long periods of time (Dannemann \& Pieri 1989). Under these conditions, the snails have been found buried $3 \mathrm{~m}$ from the margin (Paraense et al. 1955).

When prevented from surfacing, the snail switch from aerial to aquatic respiration and can remain submerged for as long as 92 days as long as the oxygen level is sufficient (Jurberg 1992). It can switch from aerobic to anaerobic respiration and survive for as long as $16 \mathrm{hr}$ in the absence of

${ }^{+}$Corresponding author. Fax: +55-21-290.1146 Received 15 July 1996

Accepted 29 November 1996 dissolved oxygen (von Brand et al. 1950), but dies of asphyxiation after longer periods of time (Rey 1956).

Survival under such diverse conditions is associated with the mechanisms of respiration. These mechanisms, however, have not been fully clarified. The respiration of $B$. glabrata is attributed to the mantle cavity, the tegument and the pseudogill (Paraense 1972). However, it is difficult to distinguish the partial or total participation of each of these organs in aerial and aquatic respiration for several reasons: (1) histologically there is no difference between the epithelia related to aquatic and aerial respiration in invertebrates in general (Carter 1931), and in B. glabrata, in particular (Pan 1958); (2) on the surface, this species breathes through a pneumostoma, filling the mantle cavity with air, a fact that characterizes aerial respiration. On the other hand, when the snail is submerged it still performs gas exchanges that characterize aquatic respiration. In this case, we cannot preferentially associate this type of respiration with the tegument or the pseudogill since both can function simultaneously; (3) there is the possibility that the air bubble, in addition to functioning as an oxygen reservoir and aiding flotation, may also function inside the mantle cavity as a physical gill since it may remove oxygen from water through nitrogen. This mechanism exists in some aquatic insects that submerge with an external bubble (Ege 1918) and has been attributed by Henderson (1963) to mol- 
lusks such as Planorbarius corneus and Lymnaea stagnalis; (4) water circulation inside the mantle cavity (Cheng \& Sullivan 1974, Sullivan \& Cheng 1974 ) is another factor that impairs the characterization of the type of respiration.

Information about the morphophysiology of an animal is important for the understanding of its biological and behavioral activities. In the present investigation we studied: (1) the morphology of the mantle cavity; (2) how the inflow and outflow of water and air are processed in the mantle cavity, as well as the biological functions of these phenomena; (3) whether the air bubble in the cavity functions as a physical gill.

\section{MATERIALS AND METHODS}

We used albino B. glabrata snails $(n=124)$ from Santa Luzia, State of Minas Gerais, Brazil, varying in diameter from 1.5 to $2.0 \mathrm{~cm}$.

Morphology of the mantle cavity (cristae and chambers) - Ten snails were immersed for $48 \mathrm{hr}$ with no access to the surface for full exposure of the pseudogill and anesthetized with $0.05 \%$ nembutal for $24 \mathrm{hr}$. The animals were killed and removed from the shell according to the technique of Rey (1956).

Longitudinal cuts were made through an incision in the mantle in the region between the renal vein and the dorsolateral cristae (Fig. 1A) so that the latter would be located on the side of the rectal cristae in the opened mantle cavity. Transversal sections $(0.5 \mathrm{~cm}$ thick) were obtained with the aid of dissecting scissors from the entire mantle cavity and fixed in Baker calcium formalin to harden the material. Images were drawn using a light camera (Wild M5 microscope) and the relevant structures were photographed with a NIKON F3 camera.

Inflow and outflow of air and water in the mantle cavity - We performed three stages of observation using video recording (Handycam $8 \mathrm{~mm}$ Sony camera) and copied them to a VHS tape of 6 hr duration, so that the tape could be shown frame by frame and stopped for drawing in sequence using a retroprojector pen and transparent paper placed on the television screen.

Stage 1 - To observe the air outflow, we placed the snail $(n=10)$ with its right surface looking up on a Petri dish containing water and then forced retraction of the cephalopodal mass into the shell with a stylet up to half of the body gyrus, thus provoking the elimination of air bubbles.

In order to observe by transparency the inflow of air, we placed the snail in the same position as before and waited for it to expose again its cephalopodal mass, thus permitting water to enter the mantle cavity and fill it completely. Using a
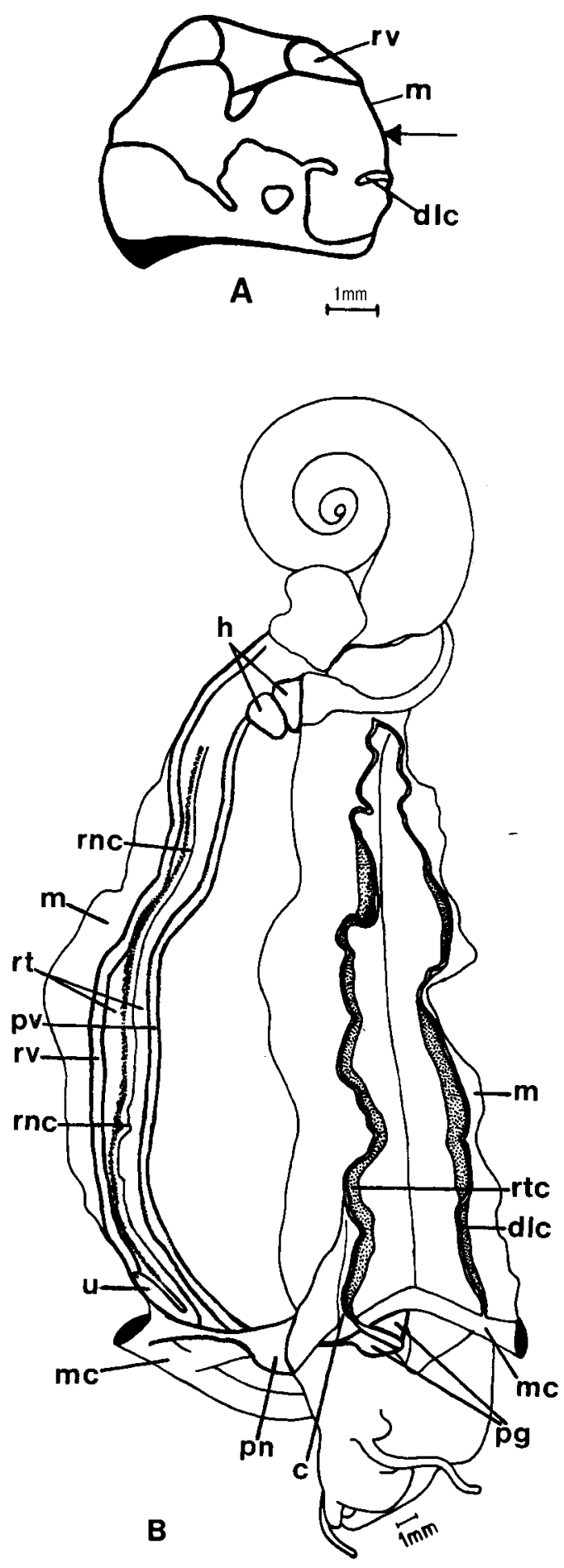

Fig. 1- A: transverse section of the mantle cavity. The arrow indicates the site where the mantle $(\mathrm{m})$ was sectioned to obtain a longitudinal section between the dorsolateral cristae (dlc) and the renal vein (rv). B: longitudinal section. $\mathrm{mc}=$ mantle collar, pg = pseudogill, $\mathrm{pn}=$ pneumostoma, $\mathrm{c}=$ crack, $\mathrm{u}=$ ureter, $\mathrm{rnc}=$ renal cristae, $\mathrm{pv}=$ pulmonary vein, $\mathrm{rt}=$ renal tube, $\mathrm{h}=$ heart, $\mathrm{rtc}=$ rectal cristae. 
syringe, we made the water level go down close to the opening of the shell, so that the snail could have access to atmospheric air without moving. As the air was progressively aspirated by the pneumostoma, we recorded the dislocation of the interface line formed by the contact of water with the penetrating air.

Stage 2 - We recorded the inflow of water into the mantle cavity of snails $(n=10)$ forced with a stylet to retract their cephalopodal mass inside the shell up to half the body gyrus, thus provoking an almost complete elimination of the water/air content of the cavity. We dried the shell externally and internally and filled the space created between the end of the retracted mass and the border of the shell with water containing diluted India ink. We placed the snail with the left surface looking up immersed in water on a Petri dish and recorded by transparency the inflow of water containing India ink.

Stage 3 - To observe the outflow of water from the mantle cavity, we prevented the snails $(n=10)$ from surfacing for $24 \mathrm{hr}$ and left them immersed in an India ink solution that filled the cavity. We removed one snail at a time and lightly dried it so that retraction of the cephalopodal mass into the shell would not occur. We then submerged it with the left surface looking up into water on a Petri dish and recorded the outflow of India ink with the video camera.

Physical gill - Russel-Hunter (1979) proposed a method which consisted of placing the mollusks in well aerated air in three different environments: air, nitrogen and oxygen, and compared the time of immersion in these three situations. If the mollusks remained submerged for a longer time when the gas phase was nitrogen instead of air, this mean that the bubble with nitrogen was receiving oxygen from water and therefore the mollusks could stay submerged longer. As a counter-test, the mollusks submitted to the situation in which the gas phase was oxygen it should remain submerged for a shorter period of time than those submitted to air, since, if the mollusks breathe exclusively through the physical gill, it would be possible for them to remove oxygen only from water and not from the bubble.

We used 84 snails divided into three groups of 28. Each group was placed inside an acrylic chamber described by Jurberg et al. (1988), containing $900 \mathrm{ml}$ of water at $23^{\circ} \mathrm{C}$. In group 1 the chamber was left open in contact with atmospheric air; in group 2, after placing the snails inside we sealed the chamber which remained attached to a nitrogen balloon. We then released nitrogen inside the chamber for $1 \mathrm{~min}$, and assumed that the gas phase of the system consisted only of nitrogen. In group 3 we followed the same procedure as in 2 but us- ing an oxygen balloon. In all three situations, we measured the amount of oxygen dissolved in the aqueous phase by the method of Winkler. For a period of $1 \mathrm{hr}$ we recorded: (a) time of permanence on the surface; (b) time of immersion; (c) frequency at which the snails climbed to the surface. Data were analyzed statistically by the Kruskal-Wallis test (Siegel 1975).

\section{RESULTS}

Morphology of the mantle cavity (cristae and chambers) - A longitudinal section shows the renal cristae located along the renal tube, flanked on the right by the pulmonary vein (left side of the snail) and on the left by the renal vein (right side of the snail). These four structures form an ensemble located on the roof of the mantle cavity (Fig. 2A, B).

The renal cristae is fully smooth and extends from the ureter to a point near the heart (Figs 1B, $2 \mathrm{~A}, \mathrm{C})$.

The rectal and dorsolateral cristae are located left to the mantle cavity. The rectal cristae is located on the floor of the cavity above the intestine and small vertical folds cover its entire length. In live snails, the renal cristae presents undulating movements that differentiate it from the remaining cristae. It starts in the pseudogill, dividing the latter structure into two portions, and it ends at the level of the heart (Figs 1B, 2A, C).

The dorsolateral cristae is located on the left lateral wall of the mantle cavity and is fully smooth. It begins in the mantle collar and ends at the level of the heart, where it joins the rectal cristae (Figs 1B, 2A, C).

The spatial arrangement of the three cristae (rectal, renal and dorsolateral) inside the mantle cavity forms three chambers: (1) air or pulmonary chamber located on the right side of the mantle cavity and visible by transparency in live albino snail only on this side (Fig. 2A, B); (2) water inflow chamber located on the upper left side of the mantle cavity; (3) water outflow chamber located on the lower left side of the mantle cavity. The last two chambers are visible by transparency in live albino snails only on this side (Fig. 2A, C).

\section{Inflow and outflow of air and water in the mantle cavity}

Stage 1 - The air or pulmonary chamber is the only one that receives atmospheric air through the pneumostoma. Before a sudden descent, this air can be slowly eliminated in the form of small bubbles and is replaced by the water that flows from the water inflow chamber, occupying the space left by the eliminated air. We noted that the snail opens the pneumostoma on the surface and atmospheric air gradually penetrates the air chamber with the 


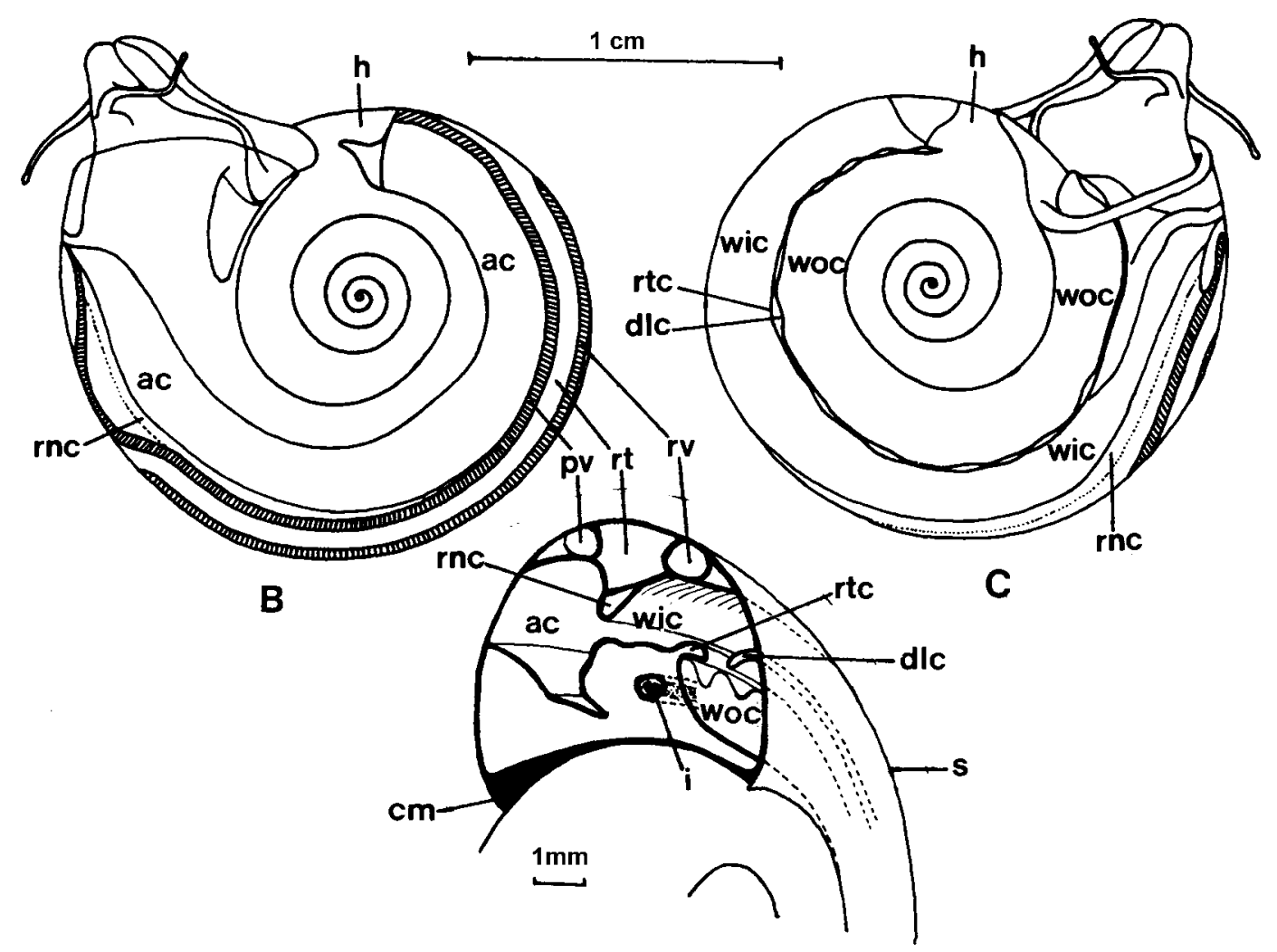

A

Fig. 2 - A: transverse section of the mantle cavity. B, C: right and left sides of the snail, respectively. pv = pulmonary vein, rv = renal vein, $\mathrm{rt}=$ renal tube, $\mathrm{rnc}=$ renal cristae, $\mathrm{rtc}=$ rectal cristae, $\mathrm{dlc}=$ dorsolateral cristae, $\mathrm{ac}=$ air chamber, wic $=$ water inflow chamber, woc $=$ water outflow chamber; $\mathrm{i}=$ intestine, $\mathrm{s}=$ shell, $\mathrm{cm}=$ columellar muscle, $\mathrm{h}=$ heart.

occurrence of two simultaneous situations: (1) the tenuous interface line formed by the contact of water inside the air chamber with the penetrating air shifts to the posterior part of the air chamber (Fig. 3); (2) the set formed by the renal tube with the renal cristae and the pulmonary and renal veins shifts longitudinally to the left side of the snail, compressing the two water chambers and provoking their narrowing. This process only ceases when the interface line reaches the bottom of the air chamber at the level of the heart.

Stages 2 and 3 - The water inflow and outflow chambers only receive water, with inflow controlled by the smaller portion of the pseudogill and outflow controlled by the larger portion.

When penetrating the cavity, the water passes through a crack which is a space located between the end of the rectal cristae in the pseudogill and the pneumostoma (Fig. 1B).

The normal inflow and outflow of water in the mantle cavity occurs when the air chamber is completely filled with air and the set formed by the renal tube, renal cristae and pulmonary and renal veins shift longitudinally to the left side of the snail (Fig. 4A).

The water circulates in the cavity entering the water inflow chamber through the crack, running longitudinally along the chamber, passing between the rectal and dorsolateral cristae and penetrates the water outflow chamber, flowing out through the anterior region of this last chamber through the larger portion of the pseudogill (Fig. 4B).

The normal flow may be altered by the inflow of water due to the increase in hydrostatic pressure, during a sudden descent, provoking partial or full elimination of air from the air chamber. The air is replaced with the water that flows from the other two chambers and the air chamber is first invaded through the posterior part at heart level and soon after through the anterior part, at times imprisoning an air bubble that remains located in an intermediate region (Fig. 4C).

The set formed by the renal tube, renal cristae and pulmonary and renal veins shifts longitudinally 

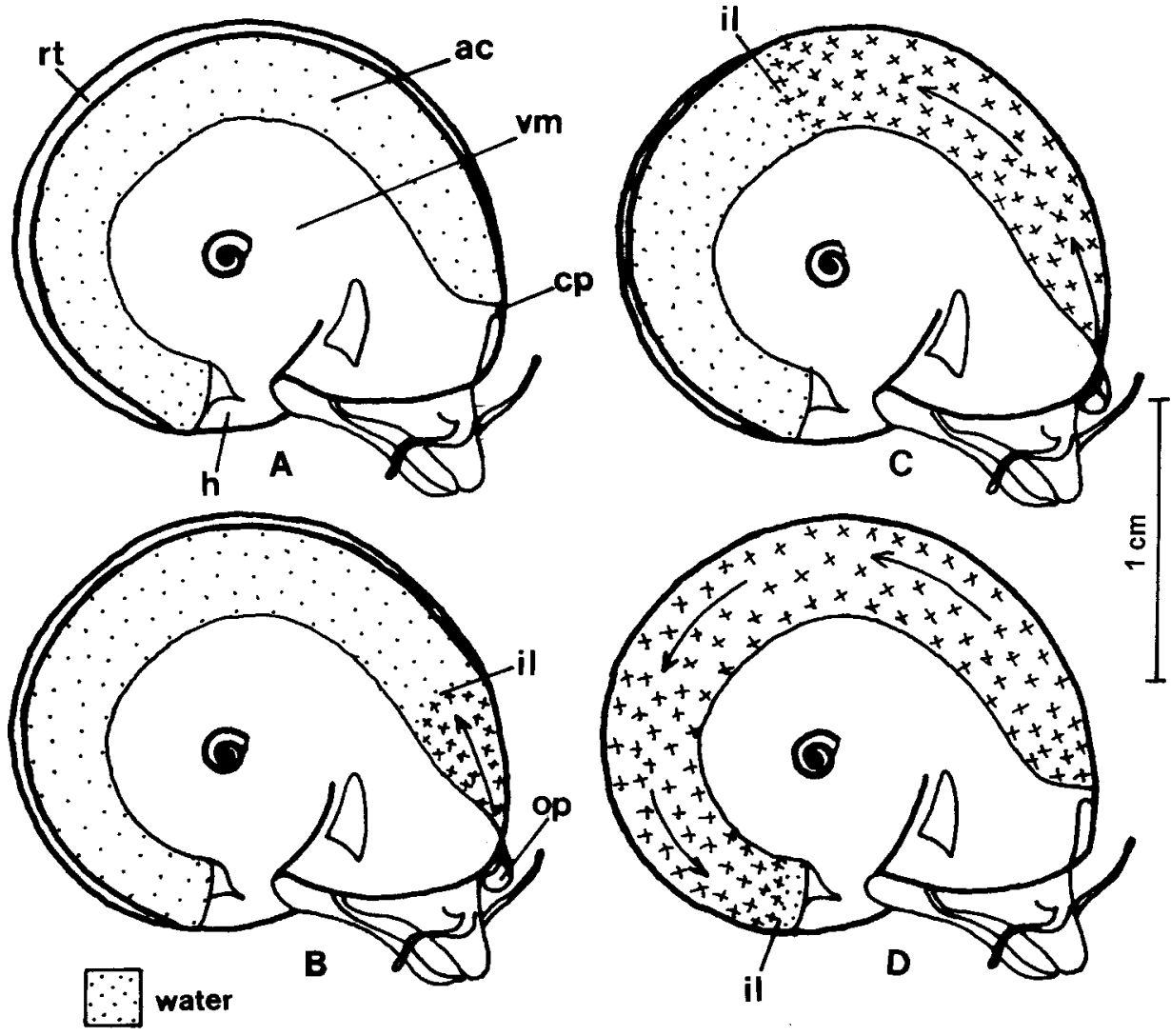

$\left[\begin{array}{l}x \times x \\ x \times x \\ x \times x\end{array}\right]$ air

Fig. 3: sequence of drawings illustrating the mechanism of air inflow into the air chamber, as indicated by the arrows. ac $=$ air chamber, $\mathrm{h}=$ heart, $\mathrm{cp}=$ closed pneumostoma, op = open pneumostoma, $\mathrm{rt}=$ renal tube, $\mathrm{il}=$ interfacial line, $\mathrm{vm}=$ visceral mass.

to the right of the snail. With this, the mantle cavity practically becomes filled with water surrounding the three cristae (Fig. 4D).

Physical gill - The mean time of permanence on the surface was $3 \mathrm{~min}$ and $15 \mathrm{sec} \pm 2 \mathrm{~min}$ and $28 \mathrm{sec}$ for the group with air, $2 \mathrm{~min}$ and $44 \mathrm{sec} \pm 2$ min and $48 \mathrm{sec}$ for the group with nitrogen and 4 min and $7 \mathrm{sec} \pm 4$ min and $18 \mathrm{sec}$ for the group with oxygen $(\mathrm{H}=2.1 ; \mathrm{p}>0.05)$.

The mean time of immersion was $56 \mathrm{~min}$ and $45 \mathrm{sec} \pm 2 \mathrm{~min}$ and $28 \mathrm{sec}$ for the group with air, $57 \mathrm{~min}$ and $16 \mathrm{sec} \pm 2 \mathrm{~min}$ and $48 \mathrm{sec}$ for the group with nitrogen and $56 \mathrm{~min}$ and $19 \mathrm{sec} \pm 4 \mathrm{~min}$ and $14 \mathrm{sec}$ for the group with oxygen.

The mean number of ascents to the surface was $3.10 \pm 1.93$ for the group with air, $2.67 \pm 1.72$ for the group with nitrogen and $2.46 \pm 1.37$ for the group with oxygen $(\mathrm{H}=1.04 ; \mathrm{p}>0.05)$.

There was no significant difference between groups in the three direct variables studied.

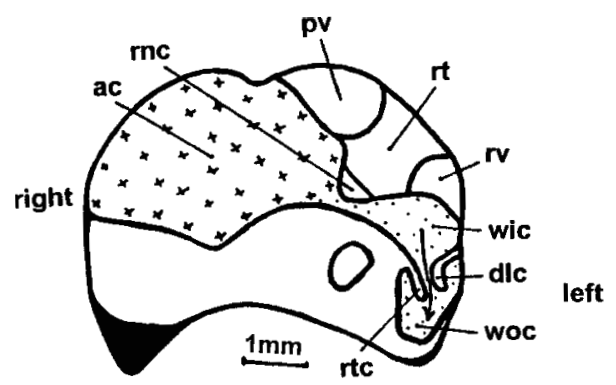

\section{water}

\section{Exir air}

Fig. 4A: transversal section of the mantle cavity showing, in normal condition, the distribution of the air and the water inside the air (ac), the water inflow (wic) and the water outflow (woc) chambers. The arrow indicates the normal direction of the water flow. $\mathrm{rnc}=$ renal cristae, $\mathrm{rtc}=$ rectal cristae, $\mathrm{dlc}=$ dorsolateral cristae, $\mathrm{pv}=$ pulmonary vein, $\mathrm{rv}=$ renal vein, $\mathrm{rt}=$ renal tube. 


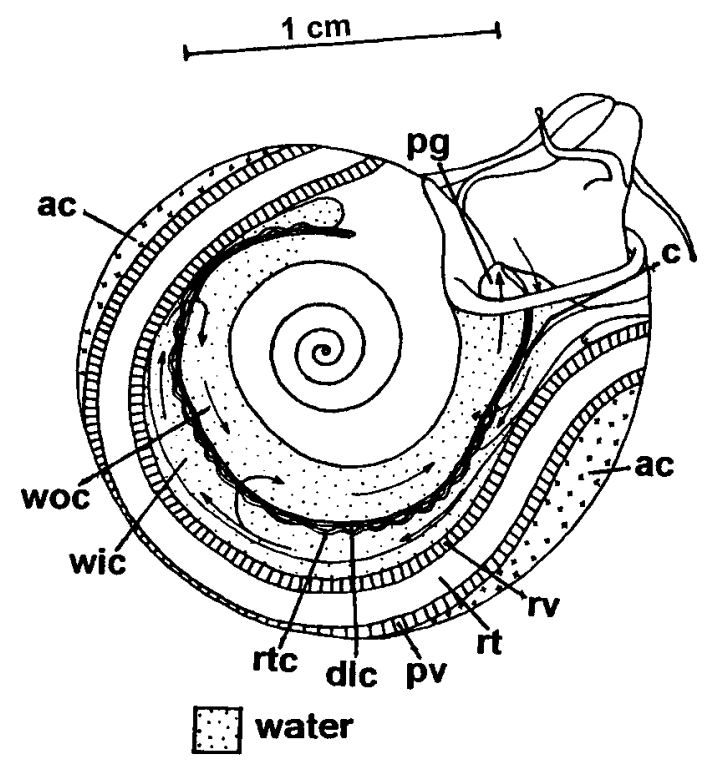

閶air
Fig. 4B: albino snail observed by transparency (left side view). The arrows indicate the normal direction of the water flow through the water inflow and outflow chambers (wic, woc). ac $=$ air chamber, $\mathrm{c}=$ crack, $\mathrm{pg}=$ pseudogill, $\mathrm{rtc}=$ rectal cristae $\mathrm{dlc}=$ dorsolateral cristae, $\mathrm{rv}=$ renal vein, $\mathrm{pv}=$ pulmonary vein, $\mathrm{rt}=$ renal tube.

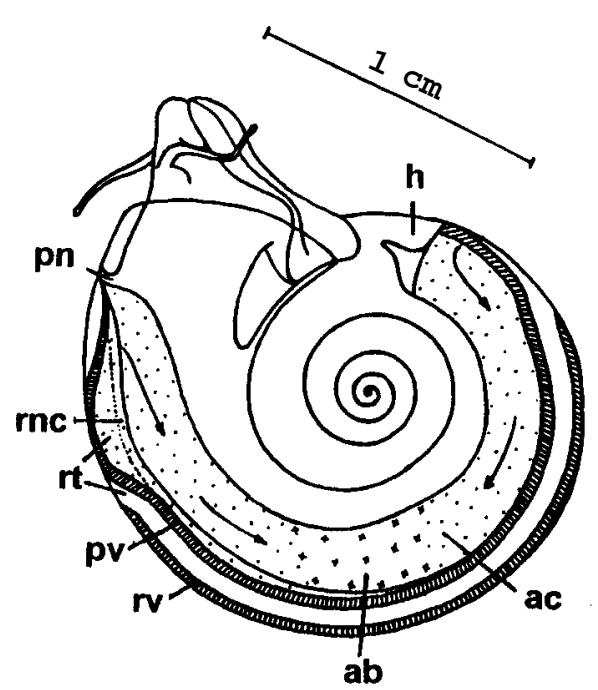

[.] water

air

Fig. 4C: albino snail observed by transparency (right side view). The arrows indicate the altered direction of the water flow invading the air chamber (ac) through the posterior and anterior parts simultaneously, imprisoning an air bubble in the middle $(\mathrm{ab}) . \mathrm{h}=$ heart, $\mathrm{rv}=$ renal vein, $\mathrm{rt}=$ renal tube, $\mathrm{pv}=$ pulmonary vein, $\mathrm{rnc}=$ renal cristae, $\mathrm{pn}=$ pneumostoma .

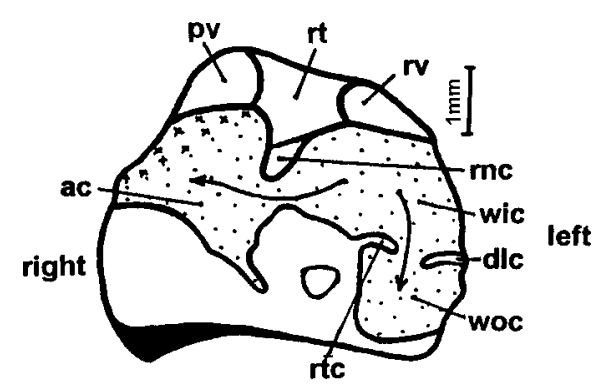

[.] water

橍 air

Fig. 4D: transversal section of the mantle cavity showing, in altered condition, the distribution of the air and the water inside the air (ac), the water inflow (wic) and the water outflow (woc) chambers. The arrows indicates the altered direction of the water flow. $\mathrm{rnc}=$ renal cristae, $\mathrm{rtc}=$ rectal cristae, $\mathrm{dlc}=$ dorsolateral cristae, $\mathrm{pv}=$ pulmonary vein, $\mathrm{rv}=$ renal vein, $\mathrm{rt}=$ renal tube.

Oxygen dissolved in water was measured before and after $1 \mathrm{hr}$ of observation, when we obtained $8.4 \mathrm{mgl}^{-1} / 8.2 \mathrm{mgl}^{-1}$ for the group with air, 8.0 $\mathrm{mgl}^{-1} / 6.5 \mathrm{mgl}^{-1}$ for the group with nitrogen and $8.5 \mathrm{mgl}^{-1} / 11.5 \mathrm{mgl}^{-1}$ for the group with oxygen, respectively.

\section{DISCUSSION}

Morphology of the mantle cavity (cristae and chambers) - The division into compartments containing air or water produced by the cristae in the mantle cavity of pulmonate snails is still a matter of debate.

Harry (1964) stated that in Chilina fluctuosa the division of the chambers is formed by the intermediate mantle cristae (dorsolateral cristae in B. glabrata) and the lateral cristae (rectal cristae in B. glabrata). This investigator, in his observations of live Bulinus tropicus, showed that these cristae occasionally create a separation (division) at least in the anterior portion of the mantle cavity. This same author suggested that in higher planorbids the division of the mantle cavity into a chamber on the right side mainly containing air and a chamber on the left side only containing water may be a recent change, but did not suggest any explanation for this change.

According to Stiglingh and van Eeden (1976), there is disagreement about whether the cristae divide the mantle cavity of $P$. corneus into two compartments.

In B. glabrata, Sullivan and Cheng (1974) were the first to show that the mantle cavity of this species is divided into two chambers filled with water 
by the temporary contact of the rectal cristae with the dorsolateral cristae. They denoted these chambers dorsal and ventral. Later, Cheng and Sullivan (1974) detected a third chamber that stored air, as confirmed by Sullivan et al. (1974). These investigators observed that an air bubble was maintained on the right side of the renal cristae but did not refer to a possible role of this cristae in the separation of the air storage chamber from the water storage chamber.

We confirmed the existence of the three chambers in B. glabrata: the first, located on the right side of the snail, is the air or pulmonary chamber, and the other two, located on the left side of the snail, are the water inflow chamber (located dorsally) and the water outflow chamber (located ventrally). The division between the last two chambers may be explained by the contiguity of the rectal cristae with the dorsolateral cristae, which join at the bottom of the mantle cavity at the level of the pericardium, and by the temporary contact of these two cristae along their apices, as observed by Sullivan and Cheng (1974). The contiguity of these two cristae was also mentioned by Stiglingh and van Eeden (1976) in B. tropicus.

We also noted that, because of the arrangement of these chambers in this species, the shell tends to lean slightly to the left of the cephalopodal mass owing to the fact that the two water chambers create a greater weight on this side than the air chamber located on the right.

We assume that the renal cristae may have the function of separating the air in the air chamber from the water in the water inflow chamber, but our doubts about this possible function of the renal cristae are due to the fact that the chambers are functional and not morphological. Furthermore, the renal cristae only occurs in B. glabrata, in the African subgenus Physopsis of the genus Bulinus according to Malek and Cheng (1974), and in the genus Helisoma according to Baker (1945).

Some mechanisms may explain the separation of the chambers: (1) by pressure, the air may keep the water only in the water inflow and outflow chambers; (2) the three cristae subdivide the cavity into three chambers, as is the case for $B$. glabrata; (3) the remaining species in the family which do not have a renal cristae - may have the three chambers (air inflow and water inflow and outflow) formed by the expansion of the rectal and dorsolateral cristae up to the opposite wall of the cavity, so as to form three chambers; (4) they may also have only two chambers, one of them containing air and the other water, the last one serving as a water inflow or outflow chamber according to need.

\section{Air and water inflow and outflow in the mantle cavity}

Functions of the air bubble - The functions of the air bubble are: flotation, oxygen reservoir, and probably physical gill.

Functions of water - Water inflow and outflow in the mantle cavity of B. glabrata have been investigated by few authors (Cheng $\&$ Sullivan 1974, Sullivan \& Cheng 1974, Sullivan et al. 1974). This may be due to: (1) the difficulty in visualizing this mechanism, as previously described in Materials and Methods (section 2 - Inflow and outflow of air and water in the mantle cavity, Stage 2); (2) the fact that water inflow into the mantle cavity of a pulmonate seems to be a paradox. However, a mantle cavity filled with water had already been observed in Arminger crista (Precht 1939), Physa fontinalis and L. peregra (Russel-Hunter 1953), C. fluctuosa (Harry 1964), and B. tropicus (Stiglingh \& van Eeden 1976). In this last species, the water flow may eliminate mucus and accumulated slime in buried specimens.

The water flow inside the mantle cavity of $B$. glabrata seems to be caused by simultaneous movements of the cristae along with the distention and retraction of the pseudogill. We do not discard that the ciliae may participate of this process.

The first function we may attribute to water inside the mantle cavity of $B$. glabrata is the transport of dissolved oxygen for gas exchange, in view of the fact that the epithelia of the cristae and of the mantle itself are compatible with this function (Pan 1958) and that some B. glabrata specimens can survive 92 days when prevented from surfacing, with their mantle cavity constantly filled with water (Jurberg 1992).

The second function we attribute to water is related to the circulation and elimination of excreta since, according to Baker (1945) and Pan (1958), the ureter opens into the mantle cavity (Fig. 4B). We noted that, close to the mantle border, the ureter curves forming a loop, more precisely towards the interior of the water inflow chamber, a fact that might indicate that the excreta run along the two water chambers and that along their path some salts may be reabsorbed by the osmoregulation mechanism since, according to Cheng and Sullivan (1977), this is one of the functions of the cristae.

The third function of water in the mantle cavity may be to maintain the temporary rigidity of the cavity with a water skeleton since, as air leaves the cavity, water penetrates it, maintaining the shape of the soft parts. This function as a water skeleton is attributed to the hemolymph (Paraense 1972), but we believe that hemolymph alone may be insufficient to maintain the shape of the mantle cavity, so that water would complement this func- 
tion. This is a function of great importance when the snail descends to greater depths, since water, when entering the cavity, equilibrates the internal pressure with the external pressure, preventing the soft parts of the snail from suffering deformation, as we had the opportunity to observe when the snails were submitted to pressures corresponding to a depth of $50 \mathrm{~m}$ (Jurberg 1992).

The fourth function of water is to control the specific weight of the snail together with air and is also responsible for the dislocation and postures of the shell.

Physical gill - The concept of physical gill was established by Comstock (1887), based on studies of some insects that dive with an air bubble around their surface and extract water by diffusion through the nitrogen contained in this bubble. These insects, when exposed to a gas phase of pure oxygen, sank rapidly and died within a short time since they were only able to extract oxygen from water through the process described above. According to Krogh (1941), the interface of the nitrogen in the air bubble with surrounding air functioned as a true gill.

The concept of physical gill was not accepted by Precht (1939) or Alberts (1966), who considered the pneumostoma to be too small an opening for contact between air (N2) and water that would permit oxygen absorption from water. However, these investigators did not consider that water can circulate inside the mantle cavity. Henderson (1963) and Jones (1961), when analyzing the content of the air bubbles, stated that in P. corneus and $L$. stagnalis the bubble may function as a physical gill.

In B. glabrata we did not find a significant difference between time of snail immersion in the presence of a pure nitrogen gas phase and in the presence of an atmospheric air gas phase. This indicates that the method of Russel-Hunter (1979) was inappropriate for the present study, or that indeed there is no physical gill function in $B$. glabrata, although this species has all the morphophysiological properties needed to use the mechanism in question to obtain oxygen, in view of the fact that water circulates inside the mantle cavity in contact with air (N2).

\section{REFERENCES}

Alberts LE 1966. Some aspects of respiratory physiology of three South African freshwater snails Bulinus (Physopsis) africanus (Krauss), Bulinus (Bulinus) tropicus (Krauss) and Lymnaea natalensis (Krauss). S Afr J Sci 62: 215-223.

Andrade RM 1959. Ecologia. In Monograph on Schistosomiasis mansoni. Rev Bras Malar 11: 171-217.

Appleton CC 1978. Review of literature on abiotic fac- tors influencing the distribution and life cycles of bilharziasis intermediate host snails. Malacol Rev 11: 1-25.

Baker FC 1945. The molluscan family Planorbidae. University Ilinois Press, xxxvi $+550 \mathrm{pp}$.

Carter GS 1931. Aquatic and aerial respiration in animals. Biol Rev 6: 2-35.

Cheng TC, Sullivan JT 1974. Mode of entry, action, and toxicity of copper molluscicides, p. 84-153. In TC Cheng, Molluscicides in Schistosomiasis Control. Academic Press Inc., New York.

Cheng TC, Sullivan JT 1977. Alterations in the osmoregulation of the pulmonate gastropod Biomphalaria glabrata due to copper. J Invert Path 29: 101-104.

Comstock JH 1887. Note on respiration of aquatic bugs. Amer Nat 21: 577-578.

Dannemann RDA, Pieri OS 1989. Anidrobiose e diapausa em Biomphalaria glabrata (Say), caramujo transmissor da esquistossomose na região nordeste. Biotemas 2: 57-68.

Deschiens R, Jadin J 1954. Viabilité des mollusques vecteurs des bilharzioses dans les eaux profondes. Bull Soc Path Exot 47: 668-671.

Ege R 1918. On the respiratory function of the air. Stores carried by some aquatic insects (Corixidae, Dysticidae and Notonecta). Z Allg Physiol 17: 81124.

Freitas JR 1976. Ecologia de vetores de doenças. O habitat primitivo da Biomphalaria glabrata. Ci e Cult 28: 212-217.

Harry HW 1964. The anatomy of Chilina fluctuosa Gray reexamined, with prolegomena on the phylogeny of the higher limnic Basommatophora (Gastropoda: Pulmonata). Malacologia 1: 355-385.

Henderson AE 1963. On the underwater weights of freshwater snails. Z Vergl Physiol 46: 467-490.

Jones JD 1961. Aspects of respiration in Planorbis corneus L. and Lymnaea stagnalis L. (Gastropoda: Pulmonata). Comp Biochem Physiol 4: 1-29.

Jurberg P 1992. Alguns aspectos do comportamento de Biomphalaria glabrata (Say, 1818), com ênfase na atividade respiratória. Instituto de Biofísica da Universidade Federal do Rio de Janeiro, Rio de Janeiro, xxv +460 pp.

Jurberg P, Schall VT, Barbosa JV, Gatti MJ, Soares MS 1987. Behavior of Biomphalaria glabrata, the intermediate host snail of Schistosoma mansoni, at different depths in water in laboratory conditions. Mem Inst Oswaldo Cruz 82: 197-208.

Jurberg P, Soares MS, Mascitelli AC, Favre TC, Barbosa JV 1988. Studies on survival, biological activities and behavior of Biomphalaria glabrata, the host snail of schistosomiasis, submitted to increased hydrostatic pressure: a technique. Mem Inst Oswaldo Cruz 83: 53-61.

Krogh A 1941. The comparative physiology of respiratory mechanisms. University of Pennsylvania Press, Philadelphia, 172 pp.

Malek EA, Cheng TC 1974. Medical and Economic Malacology. Academic Press, New York and London, 398 pp.

Olivier L, Barbosa FS 1956. Observations on vector of 
schistosomiasis mansoni kept out of water in the laboratory. II. J Parasitol 42: 277-286.

Pan CT 1958. The general histology and topographic microanatomy of Australorbis glabratus. Bull Mus Comp Zool 119: 237-299.

Paraense WL 1972. Fauna Planorbídica do Brasil, p. 213239. In CS Lacaz, RG Baruzzi, W Siqueira Jr (eds). Introdução à Geografia Médica do Brasil. Blucher, Universidade de São Paulo, São Paulo.

Paraense WL, Pereira O, Pinto DB 1955. Um aspecto da ecologia do Australorbis glabratus que favorece a reinfestação dos criadouros. Rev Serv Esp Saúde Públ 7: 573-581.

Precht H 1939. Die Lungenatmung der Susswasserpulmonaten. Z Vergl Physiol 26: 696-739.

Rey L 1956. Contribuição para o conhecimento da morfologia, biologia e ecologia dos planorbídeos brasileiros transmissores da esquistossomose. Serviço Nacional de Educação Sanitária, Rio de Janeiro, xiii + 217 pp.

Russel-Hunter WD 1953. On migrations of Lymnaea peregra (Muller), on the shores of Loch Lomond.
Proc $R$ Soc Edinburg 65: 84-105.

Russel-Hunter WD 1979. A life of invertebrates. Mac Millan Publishing, New York, 650 pp.

Siegel S 1975. Estatística não paramétrica para as ciências do comportamento. McGraw-Hill do Brasil, Rio de Janeiro, 350 pp.

Stiglingh I, van Eeden JA 1976. Functional morphology and histology of the headfoot and mantle of Bulinus tropicus (Basommatophora: Planorbidae). Natuurwetenskappe Nr. 84.

Sullivan JT, Cheng TC 1974. Structure and function of the mantle cavity of Biomphalaria glabrata (Mollusca: Pulmonata). Trans Amer Micr Soc 93: 416420.

Sullivan JT, Rodrick GE, Cheng TC 1974. A Transmission and Scanning Electron Microscopical Study of the Rectal Ridge of Biomphalaria glabrata (Mollusca: Pulmonata). Cell Tissue Res 154: 29-38.

von Brand T, Baernstein HD, Mehlman B 1950. Studies on the anaerobic metabolism and the aerobic carbohydrate consumption of some freshwater snails. Biol Bull 98: 266-277. 
Morphophysiology of the Mantle Cavity of B. glabrata - P Jurberg et al. 